\title{
Pattern of abdominal nodal spread and optimal abdominal lymphadenectomy for advanced Siewert type II adenocarcinoma of the cardia: results of a multicenter study
}

\author{
Kazumasa Fujitani $\cdot$ Isao Miyashiro $\cdot$ Shoki Mikata $\cdot$ Shigeyuki Tamura $\cdot$ Hiroshi Imamura \\ Johji Hara $\cdot$ Yukinori Kurokawa $\cdot$ Jyunya Fujita $\cdot$ Kazuhiro Nishikawa $\cdot$ Yutaka Kimura \\ Shuji Takiguchi $\cdot$ Masaki Mori $\cdot$ Yuichiro Doki
}

Received: 5 April 2012/Accepted: 15 July 2012/Published online: 16 August 2012

(C) The International Gastric Cancer Association and The Japanese Gastric Cancer Association 2012

\begin{abstract}
Background It remains uncertain whether radical lymphadenectomy combined with total gastrectomy actually contributes to long-term survival for Siewert type II adenocarcinoma of the cardia. We identified the pattern of abdominal nodal spread in advanced type II adenocarcinoma and defined the optimal extent of abdominal lymphadenectomy.

Methods Eighty-six patients undergoing R0 total gastrectomy for advanced type II adenocarcinoma were identified from the gastric cancer database of 4,884 patients. Prognostic factors were investigated by multivariate analysis. The therapeutic value of lymph node dissection for each station was estimated by multiplying the incidence of
\end{abstract}

On behalf of the Osaka University Clinical Research Group for Gastroenterological Surgery.

K. Fujitani $(\bowtie)$

Department of Surgery, Osaka National Hospital, Hoenzaka 2-1-14, Chuo-ku, Osaka 540-0006, Japan

e-mail: fujitani@onh.go.jp

I. Miyashiro

Department of Surgery, Osaka Medical Center for Cancer

and Cardiovascular Disease, Osaka, Japan

S. Mikata

Department of Surgery, Osaka Rosai Hospital,

Sakai, Japan

S. Tamura

Department of Surgery, Kansai Rosai Hospital,

Amagasaki, Japan

H. Imamura

Department of Surgery, Sakai Municipal Hospital,

Sakai, Japan metastasis by the 5-year survival rate of patients with positive nodes in each station.

Results The overall 5-year survival rate was $37.1 \%$. Age less than 65 years [hazard ratio, 0.455 (95\% confidence interval (CI), 0.261-0.793)] and nodal involvement with $\mathrm{pN} 3$ as referent [hazard ratio for $\mathrm{pN} 0,0.129(95 \% \mathrm{CI}$, 0.048-0.344); for pN1, 0.209 (95\% CI, 0.097-0.448); and for $\mathrm{pN} 2,0.376$ (95\% CI, 0.189-0.746)] were identified as significant prognosticators for longer survival. Perigastric nodes of the lower half of the stomach in positions $4 d-6$ were considered not beneficial to dissect, whereas there were substantial therapeutic benefits to dissecting the perigastric nodes of the upper half of the stomach in positions 1-3 and the second-tier nodes in positions 7 and 11 .

Conclusions Limited lymphadenectomy attained by proximal gastrectomy might suffice as an alternative to extended lymphadenectomy with total gastrectomy for obtaining

J. Hara $\cdot$ Y. Kurokawa $\cdot$ S. Takiguchi $\cdot$ M. Mori $\cdot$ Y. Doki

Department of Gastroenterological Surgery, Graduate

School of Medicine, Osaka University, Suita, Japan

J. Fujita

Department of Surgery, Toyonaka Municipal Hospital,

Toyonaka, Japan

K. Nishikawa

Department of Surgery, Osaka General Medical Center,

Osaka, Japan

Y. Kimura

Department of Surgery, NTT West Osaka Hospital,

Osaka, Japan 
potential therapeutic benefit in abdominal lymphadenectomy for advanced Siewert type II adenocarcinoma.

Keywords Advanced adenocarcinoma of the cardia . Siewert type II - Abdominal nodal spread · Optimal lymphadenectomy $\cdot$ Multicenter study

\section{Introduction}

Recent studies have reported a continuing rise in the incidence of adenocarcinoma of the gastroesophageal junction (GEJ) despite a decline in the overall incidence of gastric carcinoma in Western countries [1,2]. Adenocarcinoma of the GEJ is defined as carcinoma centered within $5 \mathrm{~cm}$ of the anatomic GEJ, which is further classified into three distinct entities (types I, II, and III) according to the anatomic location of the tumor center [3,4]. Type I carcinoma, with the tumor center located $1-5 \mathrm{~cm}$ above the anatomic GEJ and often associated with Barrett's esophagus, was reported to be the most prevalent type in Western countries $[3,5]$. In Eastern countries, type III has been reported to be the most common type, with type I tumors rarely observed [6-9]. However, an increasing trend of GEJ adenocarcinoma has recently been reported in Japan, especially in type II (true carcinoma of the cardia), which is defined as carcinoma with its center located within $1 \mathrm{~cm}$ above and $2 \mathrm{~cm}$ below the anatomic GEJ, although the incidence of type I carcinoma still remains at approximately $1 \%$ [7].

Difficulties in surgical management and an unfavorable prognosis with 5-year survival rates of 30-50\% make this disease a malignancy of great universal concern $[4,5,10$ 12]. The subclassification of GEJ carcinoma provides a useful tool for the selection of the appropriate surgical procedure [4]. Briefly, the standard procedure for type I carcinoma is a subtotal esophagectomy through a right thoracotomy with proximal gastric resection, whereas a total gastrectomy with transhiatal resection of the distal esophagus is usually performed for type III tumors [3]. With respect to the procedure of choice for type II carcinoma, there has been some debate whether a transthoracic subtotal esophagectomy, as in type I tumors, or a total gastrectomy with transhiatal resection of the distal esophagus, as in type III tumors, is optimal. However, two recent phase III trials [11, 12] demonstrated the transhiatal approach to be preferable.

Although total gastrectomy has become the procedure of choice for patients with type II adenocarcinoma because radical lymphadenectomy achieved by removing the entire stomach with all its lymphatic drainage is believed to have the best potential for long-term survival [13], there have been no prospective studies demonstrating that formal D2 nodal dissection along with total gastrectomy really contributes to long-term survival in patients with type II tumors.

In this study, we identified the pattern of abdominal nodal spread in type II adenocarcinoma of the cardia and defined the appropriate extent of abdominal lymphadenectomy for type II adenocarcinoma by evaluating the prognostic significance of each lymph node station.

\section{Patients and methods}

\section{Study population}

A review of the gastric cancer database from nine hospitals belonging to the Osaka University Clinical Research Group for Gastroenterological Surgery identified 4,884 patients who underwent gastrectomy for primary gastric adenocarcinoma between 1 January 2001 and 31 December 2005. Among these 4,884 patients, a total of 86 patients $(1.76 \%)$ who underwent microscopically curative (R0) total gastrectomy for primary cancer of the true cardia (Siewert type II) [3] were retrospectively identified on their pathological specimens and recruited into this study. Patients with early gastric cancer (pT1), tumor invading adjacent organs (pT4b), linitis plastica, systemic metastasis, positive cytology of peritoneal lavage, or concurrent malignancy within 5 years were excluded. The clinical and histopathological tumor characteristics of these 86 patients are summarized in Table 1. Patients included 67 men and 19 women with a median age of 65.5 (range, 36-85) years. All patients underwent total gastrectomy, plus distal esophagectomy through the transhiatal approach, right thoracotomy, and left thoracotomy in 71, 7, and 8 patients, respectively. Combined resection of the spleen and distal pancreas was performed in 69 and 7 patients, respectively. Histologically, 48 patients had intestinal-type adenocarcinoma and 38 patients had diffuse-type adenocarcinoma according to the Lauren classification. Median tumor size was $50 \mathrm{~mm}$ (range, 20-150 mm). Pathological T stage and nodal involvement were classified according to the 7 th edition of the Union for International Cancer Control (UICC) pTNM staging guidelines [14]. All patients had locally advanced tumors (pT2, pT3, and pT4a), of which $80 \%$ were node positive. Adjuvant chemotherapy with S-1 or other fluoropyrimidine agents was carried out only in 28 patients with no adjuvant radiotherapy because there had been no standard adjuvant treatment until 2007 when S-1, the current standard of care in Japan, was established.

Extent of abdominal lymphadenectomy

Lymph nodes were retrieved from the excised specimens and assigned to the appropriate station according to Japanese Gastric Cancer Association criteria [15] as follows: 
Table 1 Patient and tumor characteristics

\begin{tabular}{|c|c|}
\hline Patient numbers & 86 \\
\hline \multicolumn{2}{|l|}{ Gender } \\
\hline Male & 67 \\
\hline Female & 19 \\
\hline \multicolumn{2}{|l|}{ Age, years } \\
\hline Median (range) & $65.5(36-85)$ \\
\hline \multicolumn{2}{|l|}{ Type of surgery } \\
\hline Transhiatal approach & 71 \\
\hline Right thoracoabdominal approach & 7 \\
\hline Left thoracoabdominal approach & 8 \\
\hline \multicolumn{2}{|l|}{ Combined resection } \\
\hline Spleen & 69 \\
\hline Distal pancreas & 7 \\
\hline \multicolumn{2}{|l|}{ Lauren type } \\
\hline Intestinal & 48 \\
\hline Diffuse & 38 \\
\hline \multicolumn{2}{|l|}{ Tumor size $(\mathrm{mm})$} \\
\hline Median (range) & $50(20-150)$ \\
\hline \multicolumn{2}{|l|}{ Depth of invasion (pT) } \\
\hline pT2 (MP) & 11 \\
\hline pT3 (SS) & 38 \\
\hline pT4a (SE) & 37 \\
\hline \multicolumn{2}{|l|}{ No. of positive nodes (pN) } \\
\hline pN0: 0 & 17 \\
\hline pN1: 1-2 & 22 \\
\hline pN2: $3-6$ & 19 \\
\hline $\mathrm{pN} 3: \geq 7$ & 28 \\
\hline \multicolumn{2}{|l|}{ R category } \\
\hline R0 & 86 \\
\hline $\mathrm{R} 1 / 2$ & 0 \\
\hline
\end{tabular}

no. 1, right paracardial; no. 2, left paracardial; no. 3, lesser curvature; no. 4sa, greater curvature along the short gastric vessels; no. $4 \mathrm{sb}$, greater curvature along the left gastroepiploic artery; no. 4d, greater curvature along the right gastroepiploic artery; no. 5, suprapyloric along the right gastric artery; no. 6, infrapyloric at the base of the right gastroepiploic artery; no. 7, left gastric artery; no. 8, suprapancreatic along the common hepatic artery; no. 9, celiac trunk; no. 10, splenic hilum; and no. 11, suprapancreatic along the splenic artery. The preferred lymph node dissection was a D2 abdominal lymphadenectomy (i.e., dissection of nodes in stations 1-11) with the paraesophageal, lower posterior mediastinal, and diaphragmatic nodes. A complete D2 dissection was not achieved in 17 patients. Abdominal nodal spread was examined thoroughly for each lymph node station, and both the number and site of nodal metastasis were evaluated for nodal staging $(\mathrm{pN})$. The frequency of nodal metastasis in each abdominal station was also studied in all 86 patients.
Survival analysis

All patients were followed for a minimum of 5 years or until death. None was lost to follow-up. Overall survival (OS) was defined as the time from the date of surgical resection to the date of death from any cause or last followup. When calculating disease-specific survival, deaths from causes other than relapsed disease were treated as censored cases at the time of death. Univariate analysis was used to assess the association between each clinicopathological factor and OS. Multivariate analysis was performed to identify variables independently associated with survival. Postoperative deaths were not excluded from the survival analyses.

Therapeutic value of lymph node dissection

The therapeutic value of lymph node dissection for each station was estimated by multiplying the incidence of metastasis by the 5-year survival rate of patients with positive nodes in that station [16]. The incidence of metastasis was calculated by dividing the number of patients with metastasis in each station by the number of patients who underwent dissection of that station. The 5-year survival rate of patients with positive nodes in each station was calculated independently for each lymph node station, without any reference to nodal metastasis to other stations.

Statistical analysis

SAS statistical software 9.1 (SAS Institute, Cary, NC, USA) was used for all statistical analyses, and a $P$ value less than 0.05 was considered statistically significant. Survival rates were calculated according to the KaplanMeier method, and differences were evaluated by the logrank test. A Cox proportional hazards regression model was used to identify prognostic factors for survival.

\section{Results}

Distribution of nodal metastases

Figure 1 shows the distribution of nodal metastases to each lymph node station. Overall, 69 of the 86 patients $(80.2 \%)$ showed some involvement of the abdominal nodes. There was a substantially higher frequency of metastatic spread to the perigastric nodes of the upper half of the stomach in positions 1-3 as well as to the second-tier nodes in positions 7 and 11, whereas the perigastric nodes of the lower half of the stomach in positions $4 \mathrm{~d}-6$, and the second-tier node at the splenic hilum (no. 10), were less frequently involved. 
Fig. 1 Frequency of nodal involvement to each abdominal lymph node station for the 86 patients under study. Lymph node stations are classified according to Japanese criteria 17

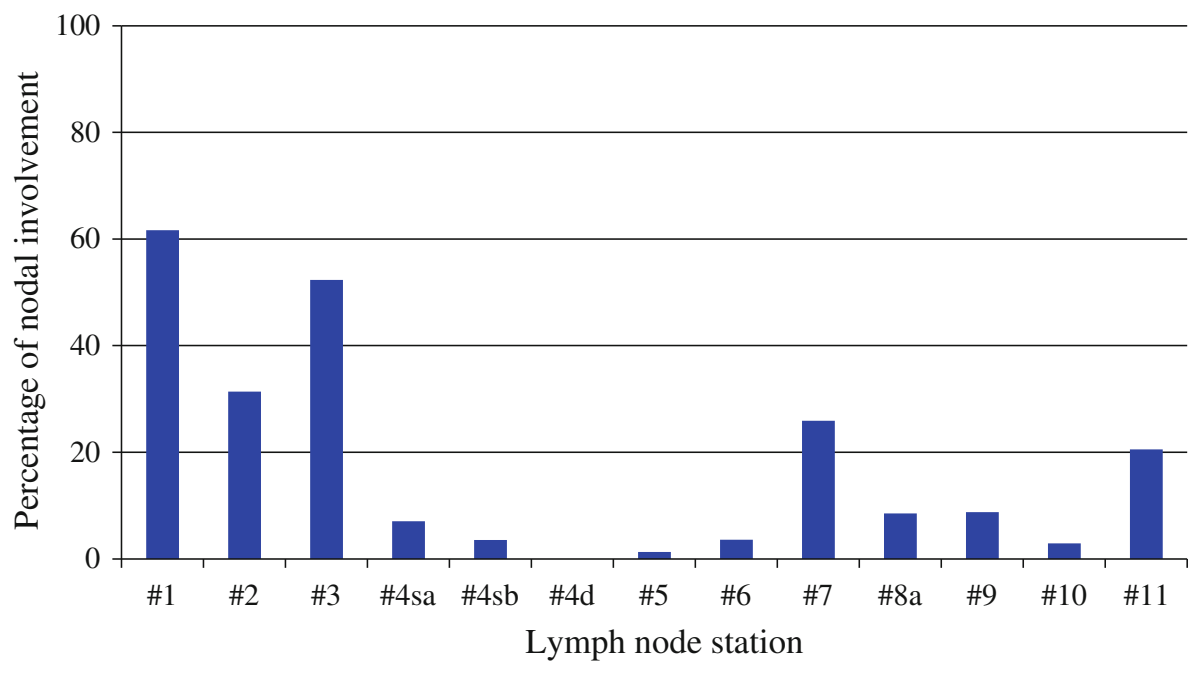

Correlation between survival and nodal involvement

During the follow-up period, 59 of the 86 patients died, of whom 48 died of relapsed disease and 11 from other causes such as cerebral infarction in 1, abrupt cardiac arrest in 2, arrhythmia in 1, pneumonia in 2 , lung cancer in 2, colon cancer in 1, postoperative complications during the hospital stay in 1 (operative mortality rate, $1.2 \%$ ), and no details specified but classified as other cause of death in 1 . The overall 5-year survival rate was $37.1 \%$, with median survival time (MST) of 1,210 days; the disease-specific 5-year survival rate was $44.8 \%$ with MST of 1,522 days. As shown in Table 2, multivariate analysis confirmed the independent prognostic value of age less than 65 years [hazard ratio, 0.455 (95\% confidence interval (CI), 0.261-0.793)] and nodal involvement with $\mathrm{pN} 3$ as referent [hazard ratio for $\mathrm{pN} 0,0.129$ (95\% CI, 0.048-0.344); for pN1, 0.209 (95\% CI, 0.097-0.448); and for pN2, 0.376 (95\% CI, 0.189-0.746)]. Overall survival according to the presence of nodal metastasis for each station is depicted in Table 3.

Potential benefit from lymph node dissection

The incidence of metastasis ranged from $0 \%$ to $61.6 \%$, and the overall 5-year survival rate of patients with lymph node metastasis ranged from $0 \%$ to $50.0 \%$ in the perigastric stations. The incidence of metastasis was between $2.9 \%$ and $25.9 \%$ in the second-tier nodes (no. 7 through 11 ), and the 5-year survival rate ranged from $14.3 \%$ to $50.0 \%$. Based on these results, the therapeutic value of lymph node dissection for each station was estimated as shown in Table 3. For some perigastric lymph node stations (no. 4d, 5, 6), dissection was considered to be not beneficial. Similarly, in terms of the disease-specific 5-year survival rate of affected patients that ranged from $0 \%$ to $50.0 \%$ in perigastric stations and from $14.3 \%$ to $50.0 \%$ in the second-tier nodes, lymph node stations numbered $4 \mathrm{~d}$, 5 , and 6 were deemed unnecessary to dissect (Table 4). In contrast, substantially higher therapeutic value were observed in the perigastric nodes of the upper half of the stomach in positions 1-3 as well as in the second-tier nodes in positions 7 and 11, as shown in Tables 3 and 4 .

\section{Discussion}

There have been several reports regarding the pattern of abdominal lymph node spread of Siewert type II adenocarcinoma [17-20]. Italian investigators reported that 44 of 62 patients (71 \%) with pT2-4 Siewert type II tumors had lymph node metastases, and a high frequency of nodal involvement in the perigastric nodes of the upper half of the stomach (right paracardial $50 \%$, left paracardial $32 \%$, lesser curvature $53 \%$ ) was seen, in contrast to the fairly low percentage of metastases in the lymph nodes along the right gastroepiploic artery (7\%), suprapyloric ( $2 \%)$, and infrapyloric lymph nodes $(2 \%)$ [17, 18]. These results were consistent with our findings as shown in Table 1 and Fig. 1, in which metastatic nodal spread was seen in $80 \%$ of patients with a striking contrast in the frequency between the perigastric nodes of the upper half of the stomach in positions 1-3 and those of the lower half of the stomach in positions $4 \mathrm{~d}-6$. With regard to the second-tier stations, lymph nodes along the left gastric artery (station 7) were affected in a substantial percentage of patients (18-65\%) with type II tumors in previous reports [5, 17-22], which was compatible with our findings shown in Fig. 1. A low percentage of metastases to the second-tier nodes at the splenic hilum was observed in this study (2.9\%), which is also in accordance with previous reports (3.9-5.0 \%) [18-20]. A precise understanding of how type II adenocarcinoma spreads to abdominal lymph nodes helps guide the surgeon when choosing the appropriate type of resection and lymphadenectomy. 
Table 2 Survival according to clinicopathological characteristics

\begin{tabular}{|c|c|c|c|c|c|c|c|}
\hline \multirow[t]{2}{*}{ Characteristics } & \multicolumn{4}{|c|}{ Univariate analysis } & \multicolumn{3}{|c|}{ Multivariate analysis } \\
\hline & No. of patients & $\begin{array}{l}\text { Median survival } \\
\text { time (MST) (days) }\end{array}$ & $\begin{array}{l}5 \text {-year } \\
\text { survival rate }(\%)\end{array}$ & $P$ & Hazard ratio & $95 \% \mathrm{CI}$ & $P$ \\
\hline \multicolumn{8}{|l|}{ Gender } \\
\hline Male & 67 & 1,211 & 38.7 & 0.3198 & 0.852 & $0.464-1.565$ & 0.6053 \\
\hline Female & 19 & 1,073 & 31.6 & & & & \\
\hline \multicolumn{8}{|l|}{ Age (years) } \\
\hline$<65$ & 40 & 1,855 & 52.5 & 0.0231 & 0.455 & $0.261-0.793$ & 0.0055 \\
\hline$\geq 65$ & 46 & 939 & 23.7 & & & & \\
\hline \multicolumn{8}{|l|}{ Lauren type } \\
\hline Intestinal & 48 & 1,299 & 39.4 & 0.6111 & 1.209 & $0.678-2.160$ & 0.5197 \\
\hline Diffuse & 38 & 1,073 & 34.2 & & & & \\
\hline \multicolumn{8}{|l|}{ Depth of invasion (pT) } \\
\hline pT2 (MP) & 11 & 1,855 & 54.5 & 0.4474 & 0.876 & $0.351-2.185$ & 0.7758 \\
\hline pT3 (SS) & 38 & 1,299 & 36.8 & & 0.968 & $0.556-1.685$ & 0.9075 \\
\hline pT4a (SE) & 37 & 905 & 32.4 & & & & \\
\hline \multicolumn{8}{|l|}{ No. of positive nodes (pN) } \\
\hline pNO: 0 & 17 & $>3,382$ & 64.7 & $<0.0001$ & 0.129 & $0.048-0.344$ & $<0.0001$ \\
\hline pN1: $1-2$ & 22 & 1,855 & 54.5 & & 0.209 & $0.097-0.448$ & $<0.0001$ \\
\hline pN2: $3-6$ & 19 & 1,522 & 31.6 & & 0.376 & $0.189-0.746$ & 0.0052 \\
\hline $\mathrm{pN} 3: \geq 7$ & 28 & 526 & 10.7 & & & & \\
\hline \multicolumn{8}{|l|}{ Level of positive nodes } \\
\hline pNO & 17 & $>3,382$ & 64.7 & 0.0113 & & & \\
\hline First-tier (no. 1-6) & 33 & 1,339 & 33.3 & & & & \\
\hline Second-tier (no. 7-11) & 36 & 848 & 27.8 & & & & \\
\hline
\end{tabular}

In this study, long-term survival was mostly limited to the patients with fewer than 7 metastatic nodes, and the independent prognostic value of nodal involvement was demonstrated in the multivariate analysis. Similar to these results, the involvement of second-tier lymph nodes [6, 10, $23]$ and the presence of more than 6 metastatic nodes [18, $19,21]$ have already been reported as negative prognostic factors in GEJ adenocarcinoma. Although age less than 65 years was identified as a significant positive prognostic factor, the depth of invasion (pT) was not an independent determinant of survival, as shown in Table 2, which is supported by other report [19]. In our series, 48 patients died of relapsed disease, involving nodal recurrence in 29 patients (4 cervical, 7 mediastinal, 20 para-aortic), hematogenous (liver, lung, bone, adrenals, brain, skin) recurrence in 23 patients, peritoneal dissemination in 7 patients, and local relapse in 4 patients. Both para-aortic lymph node metastasis and hematogenous metastasis were the predominant mode of recurrence, with peritoneal dissemination being less frequent; this was consistent with previous reports [19, 24].

Although surgical treatment with sufficient lymphadenectomy aimed at complete removal of tumor is the mainstay of treatment, the optimal extent of lymph node dissection for advanced type II carcinoma of the cardia remains unclear. When deciding whether dissection of a particular lymph node station could be a part of the optimal lymphadenectomy, the frequency of metastasis to a given lymph node station and the proportion of long-term survivors among patients with metastasis to that station are both important factors to consider. A particular lymph node station is considered clinically irrelevant to dissect unless (1) metastasis to the station is commonly observed and (2) long-term survivors exist among patients with metastasis dissected at that station [16]. According to this concept, the therapeutic value of lymph node dissection for each station was estimated by multiplying the incidence of metastasis and the 5-year survival rate of patients with metastasis dissected at that station [16] (Tables 3, 4). Dissection of the paracardial and lesser curvature nodes yielded the highest potential therapeutic benefit, whereas perigastric lymph node stations numbered $4 \mathrm{~d}, 5$, and 6 and the second-tier nodes at the splenic hilum (no. 10) were considered nonbeneficial to dissect in terms of both overall and diseasespecific survival. Similar results have been obtained in two recent reports [19, 20]. However, in marked contrast to our current study, Yamashita et al. included a significant proportion of patients with early gastric (pT1) cancer $(22.7 \%)$ 
Table 3 Estimated benefit from lymph node dissection in each station, according to the incidence of lymph node metastasis and overall 5 -year survival rate of each station

\begin{tabular}{|c|c|c|c|c|}
\hline $\begin{array}{l}\text { Lymph node } \\
\text { station }\end{array}$ & $\begin{array}{l}\text { Incidence of } \\
\text { metastasis } \\
(\%)\end{array}$ & $\begin{array}{l}\text { MST } \\
\text { (days) }\end{array}$ & $\begin{array}{l}\text { Overall } \\
5 \text {-year } \\
\text { survival } \\
\text { rate }(\%)\end{array}$ & $\begin{array}{l}\text { Estimated } \\
\text { therapeutic } \\
\text { value }\end{array}$ \\
\hline $\begin{array}{l}1 \text { Right } \\
\text { paracardial }\end{array}$ & $61.6(53 / 86)$ & 848 & 26.4 & 16.3 \\
\hline 2 Left paracardial & $31.4(27 / 86)$ & 905 & 18.5 & 5.8 \\
\hline 3 Lesser curvature & $52.3(45 / 86)$ & 848 & 22.2 & 11.6 \\
\hline $\begin{array}{l}\text { 4sa Short gastric } \\
\text { vessels }\end{array}$ & $7.0(6 / 86)$ & 2,171 & 50.0 & 3.5 \\
\hline $\begin{array}{l}\text { 4sb Left } \\
\text { gastroepiploic } \\
\text { artery }\end{array}$ & $3.5(3 / 86)$ & 466 & 33.3 & 1.2 \\
\hline $\begin{array}{l}\text { 4d Right } \\
\text { gastroepiploic } \\
\text { artery }\end{array}$ & $0(0 / 86)$ & - & - & 0 \\
\hline 5 Suprapyloric & $1.2(1 / 86)$ & 329 & 0 & 0 \\
\hline 6 Infrapyloric & $3.5(3 / 86)$ & 905 & 33.3 & 1.2 \\
\hline $\begin{array}{l}7 \text { Left gastric } \\
\text { artery }\end{array}$ & $25.9(22 / 85)$ & 850 & 22.7 & 5.9 \\
\hline $\begin{array}{l}\text { 8a Common } \\
\text { hepatic artery }\end{array}$ & $8.5(7 / 82)$ & 781 & 28.6 & 2.4 \\
\hline 9 Celiac trunk & $8.8(7 / 80)$ & 329 & 14.3 & 1.3 \\
\hline 10 Splenic hilum & $2.9(2 / 69)$ & 1,990 & 50.0 & 1.5 \\
\hline 11 Splenic artery & $20.5(15 / 73)$ & 846 & 40.0 & 8.2 \\
\hline
\end{tabular}

Data in parentheses are number of patients with metastasis in each station/number of patients undergoing lymph node dissection. Estimated therapeutic value corresponds to the percentage of patients who will benefit from dissection of each lymph node station MST mean survival time

and those undergoing proximal gastrectomy (24.8\%). Hosokawa et al. reported that $19.6 \%$ of the patients in the Siewert type II cohort had pT1 disease, and the therapeutic value of lymph node dissection was calculated for the whole population of GEJ carcinoma patients without taking into account the classification of the three distinct types. Although these findings would be helpful in defining the optimal extent of nodal dissection and the most appropriate extent of gastric resection, a prospective randomized controlled trial comparing total gastrectomy plus extended lymphadenectomy with proximal gastrectomy plus limited lymphadenectomy should be conducted to establish the optimal surgical approach for advanced type II carcinoma. With respect to the role of splenectomy combined with nodal dissection at the splenic hilum, it will be clarified as the results of a Japanese prospective trial in which more than 500 patients with $\mathrm{T} 2$ or deeper carcinoma in the proximal third of the stomach were randomized to total gastrectomy plus either splenectomy or spleen preservation [25].

In this study, we excluded patients with early carcinoma (pT1). In early gastric cancer of the true cardia, abdominal
Table 4 Estimated benefit from lymph node dissection in each station, according to the incidence of lymph node metastasis and disease-specific 5-year survival rate of each station

\begin{tabular}{|c|c|c|c|c|}
\hline $\begin{array}{l}\text { Lymph node } \\
\text { station }\end{array}$ & $\begin{array}{l}\text { Incidence of } \\
\text { metastasis } \\
(\%)\end{array}$ & $\begin{array}{l}\text { MST } \\
\text { (days) }\end{array}$ & $\begin{array}{l}\text { Disease- } \\
\text { specific } \\
\text { 5-year } \\
\text { survival } \\
\text { rate }(\%)\end{array}$ & $\begin{array}{l}\text { Estimated } \\
\text { therapeutic } \\
\text { value }\end{array}$ \\
\hline 1 Right paracardial & $61.6(53 / 86)$ & 848 & 24.5 & 15.1 \\
\hline 2 Left paracardial & $31.4(27 / 86)$ & 939 & 22.7 & 7.1 \\
\hline 3 Lesser curvature & $52.3(45 / 86)$ & 1,210 & 25.7 & 13.4 \\
\hline $\begin{array}{l}\text { 4sa Short gastric } \\
\text { vessels }\end{array}$ & $7.0(6 / 86)$ & 2,171 & 50.0 & 3.5 \\
\hline $\begin{array}{l}\text { 4sb Left } \\
\text { gastroepiploic } \\
\text { artery }\end{array}$ & $3.5(3 / 86)$ & 466 & 33.3 & 1.2 \\
\hline $\begin{array}{l}\text { 4d Right } \\
\text { gastroepiploic } \\
\text { artery }\end{array}$ & $0(0 / 86)$ & - & - & 0 \\
\hline 5 Suprapyloric & $1.2(1 / 86)$ & 329 & 0 & 0 \\
\hline 6 Infrapyloric & $3.5(3 / 86)$ & 1,925 & 50.0 & 1.8 \\
\hline 7 Left gastric artery & $25.9(22 / 85)$ & 850 & 27.4 & 7.1 \\
\hline $\begin{array}{l}\text { 8a Common hepatic } \\
\text { artery }\end{array}$ & $8.5(7 / 82)$ & 781 & 28.6 & 2.4 \\
\hline 9 Celiac trunk & $8.8(7 / 80)$ & 329 & 14.3 & 1.3 \\
\hline 10 Splenic hilum & $2.9(2 / 69)$ & 1,990 & 50.0 & 1.5 \\
\hline 11 Splenic artery & $20.5(15 / 73)$ & 1,211 & 35.2 & 7.2 \\
\hline
\end{tabular}

lymph node involvement is known to be limited to the perigastric nodes of the upper half of the stomach and the lymph nodes of the celiac trunk [17]. Based on these patterns of abdominal nodal spread and the virtual absence of lymph node metastases, a limited resection of the distal esophagus, cardia, and proximal stomach is commonly performed and is considered to provide adequate disease control for early carcinoma of the true cardia [26].

On the other hand, there have been some controversies regarding the appropriate extent of gastric resection and the therapeutic value of extended lymphadenectomy for the treatment of advanced adenocarcinoma of the cardia $[3,13$, $17,19,20]$. Some investigators advocate total gastrectomy because of the possible metastasis to the distal perigastric stations numbered $4 \mathrm{~d}, 5$, and $6[3,17]$. However, similar to our results, the frequency of metastasis to these distal stations was less than $7 \%$ [6, 17-19], and few 5-year survivors existed among patients with metastasis to the nodes numbered $4 d, 5$, and $6[6,19,20]$. These findings suggest that resection of these stations is likely to have little impact on the survival of patients with type II carcinoma. If these nodes can be omitted from the routine lymphadenectomy procedure, proximal gastrectomy might suffice as an alternative to total gastrectomy [27, 28]. However, some investigators reported a survival trend in 
favor of total gastrectomy [13]. Others pointed out there were no differences in the 5-year survival rate as well as in operative mortality between total gastrectomy versus proximal gastrectomy for advanced (pT2-pT4) type II and III carcinoma [6, 27-30]. Of note, it has never been clarified whether proximal gastrectomy can really provide some benefits, such as a better postoperative quality of life, when compared with total gastrectomy in patients with carcinoma of the cardia. As opposed, proximal gastrectomy would induce intractable reflux more often than in cases of total gastrectomy, depending on the distance of resected abdominal esophagus and the size of the remnant stomach. In addition, patients after proximal gastrectomy were demonstrated to fare less well than those after total gastrectomy in most function and symptom scales, such as reflux, nausea/vomiting, eating restrictions, and anxiety scales, using validated gastric cancer-specific questionnaires throughout the first 12-month period following gastrectomy [31]. The optimal extent of gastric resection and appropriate lymphadenectomy, which achieves complete histological negative margins with a reconstruction that yields optimal long-term functional outcome, still remains uncertain because of a lack of prospective randomized trials for the treatment of advanced type II adenocarcinoma.

In conclusion, we investigated the pattern of abdominal nodal spread and its prognostic significance in advanced Siewert type II adenocarcinoma. Limited lymphadenectomy with proximal gastrectomy could be an alternative to extended lymphadenectomy with total gastrectomy for obtaining the potential therapeutic benefit in abdominal lymphadenectomy for advanced Siewert type II adenocarcinoma. Although to the best of our knowledge the present study is the first multicenter study with the third largest sample size of 86 patients with advanced type II adenocarcinoma in the literature [5, 6, 8, 9, 17-22] (the first and second largest studies were conducted by Feith et al. [5] with 406 advanced cases and by Yamashita et al. [19] with 174 advanced patients, respectively), the retrospective nature of this study warrants further studies focusing on postoperative quality of life and long-term survival to discriminate whether total gastrectomy plus extended lymphadenectomy or proximal gastrectomy plus limited lymphadenectomy is the optimal surgical procedure to treat advanced Siewert type II adenocarcinoma.

\section{Conflict of interest None.}

\section{References}

1. Wu H, Rusiecki JA, Zhu K, Potter J, Devesa SS. Stomach carcinoma incidence patterns in the United States by histologic type and anatomic site. Cancer Epidemiol Biomark Prev. 2009;18: 1945-52.
2. Steevens J, Botterweck AA, Dirx MJ, van den Brandt PA, Schouten LJ. Trends in incidence of oesophageal and stomach cancer subtypes in Europe. Eur J Gastroenterol Hepatol. 2010;22: 669-78.

3. Siewert JR, Stein HJ. Carcinoma of the cardia: carcinoma of the gastroesophageal junction-classification, pathology and extent of resection. Dis Esophagus. 1996;9:173-82.

4. Siewert JR, Feith M, Stein HJ. Biologic and clinical variations of adenocarcinoma at the esophago-gastric junction: relevance of a topographic-anatomic subclassification. J Surg Oncol. 2005;90: 139-46.

5. Feith M, Stein HJ, Siewert JR. Adenocarcinoma of the esophagogastric junction: surgical therapy based on 1602 consecutive resected patients. Surg Oncol Clin N Am. 2006;15:751-64.

6. Kodera Y, Yamamura Y, Shimizu Y, Torii A, Hirai T, Yasui K, et al. Adenocarcinoma of the gastroesophageal junction in Japan: relevance of Siewert's classification applied to 177 cases resected at a single institution. J Am Coll Surg. 1999;189:594-601.

7. Kusano C, Gotoda T, Khor CJ, Katai H, Kato H, Taniguchi H, et al. Changing trends in the proportion of adenocarcinoma of the esophagogastric junction in a large tertiary referral center in Japan. J Gastroenterol Hepatol. 2008;23:1662-5.

8. Chung JW, Lee GH, Choi KS, Kim DH, Jung KW, Song HJ, et al. Unchanging trend of esophagogastric junction adenocarcinoma in Korea: experience at a single institution based on Siewert's classification. Dis Esophagus. 2009;22:676-81.

9. Fang WL, Wu CW, Chen JH, Lo SS, Hsieh MC, Shen KH, et al. Esophagogastric junction adenocarcinoma according to Siewert classification in Taiwan. Ann Surg Oncol. 2009;16:3237-44.

10. Steup WH, De Leyn P, Deneffe G, van Raemdonck D, Coosemans W. Tumors of the esophagogastric junction. Long-term survival in relation to the pattern of lymph node metastasis and a critical analysis of the accuracy or inaccuracy of pTNM classification. J Thorac Cardiovasc Surg. 1996;111:85-94.

11. Sasako M, Sano T, Yamamoto S, Sairenji M, Arai K, Kinoshita $\mathrm{T}$, et al. Left thoracoabdominal approach versus abdominaltranshiatal approach for gastric cancer of the cardia or subcardia: a randomised controlled trial. Lancet Oncol. 2006;7:644-51.

12. Omloo JM, Lagarde SM, Hulscher JB, Reitsma JB, Fockens P, van Dekken $\mathrm{H}$, et al. Extended transthoracic resection compared with limited transhiatal resection for adenocarcinoma of the mid/ distal esophagus: five-year survival of a randomized clinical trial. Ann Surg. 2007;246:992-1000.

13. Stipa F, Ferri M, Aromatario C, Stipa S. Carcinoma of the cardia: is there a place for proximal gastric resection in cancer of the cardia? Dis Esophagus. 1996;9:183-6.

14. Sobin LH, Gospodarowicz MK, Wittekind CH. TNM classification of malignant tumours. 7th ed. Oxford: Wiley-Blackwell; 2009.

15. Japanese classification of gastric carcinoma: 2nd English edition. Gastric Cancer 1998;1:10-24.

16. Sasako M, McCulloch P, Kinoshita T, Maruyama K. New method to evaluate the therapeutic value of lymph node dissection for gastric cancer. Br J Surg. 1995;82:346-51.

17. de Manzoni G, Morgagni P, Roviello F, Di Leo A, Saragoni L, Marrelli D, et al. Nodal abdominal spread in adenocarcinoma of the cardia. Results of a multicenter prospective study. Gastric Cancer. 1998;1:146-51.

18. Pedrazzani C, de Manzoni G, Marrelli D, Giacopuzzi S, Corso G, Minicozzi AM, et al. Lymph node involvement in advanced gastroesophageal junction adenocarcinoma. J Thorac Cardiovasc Surg. 2007;134:378-85.

19. Yamashita H, Katai H, Morita S, Saka M, Taniguchi H, Fukagawa T. Optimal extent of lymph node dissection for Siewert type II esophagogastric junction carcinoma. Ann Surg. 2011;254: 274-80. 
20. Hosokawa Y, Kinoshita T, Konishi M, Takahashi S, Gotohda N, Kato Y, et al. Clinicopathological features and prognostic factors of adenocarcinoma of the esophagogastric junction according to Siewert classification: experiences at a single institution in Japan. Ann Surg Oncol. 2012;19:677-83.

21. Dresner SM, Lamb PJ, Bennett MK, Hayes N, Griffin SM. The pattern of metastatic lymph node dissemination from adenocarcinoma of the esophagogastric junction. Surgery (St. Louis). 2001;129:103-9.

22. Yuasa N, Miyake H, Yamada T, Ebata T, Nimura Y, Hattori T. Clinicopathologic comparison of Siewert type II and III adenocarcinomas of the gastroesophageal junction. World J Surg. 2006;30:364-71.

23. Lagarde SM, Cense HA, Hulscher JB, Tilanus HW, Ten Kate FJ, Obertop $\mathrm{H}$, et al. Prospective analysis of patients with adenocarcinoma of the gastric cardia and lymph node metastasis in the proximal field of the chest. Br J Surg. 2005;92:1404-8.

24. Wayman J, Bennett MK, Raimes SA, Griffin SM. The pattern of recurrence of adenocarcinoma of the esophago-gastric junction. Br J Cancer. 2002;86:1223-9.

25. Sano T, Yamamoto S, Japan Clinical Oncology Group Study JCOG 0110-MF. Randomized controlled trial to evaluate splenectomy in total gastrectomy for proximal gastric carcinoma: Japan Clinical Oncology Group study JCOG 0110-MF. Jpn J Clin Oncol. 2002;32:363-4.

26. Stein HJ, Feith M, Mueller J, Werner M, Siewert JR. Limited resection for early adenocarcinoma in Barrett's esophagus. Ann Surg. 2000;232:733-42.

27. Jakl RJ, Miholic J, Koller R, Markis E, Wolner E. Prognostic factors in adenocarcinoma of the cardia. Am J Surg. 1995;169:316-9.

28. Harrison LE, Karpeh MS, Brennan MF. Total gastrectomy is not necessary for proximal gastric cancer. Surgery (St. Louis). 1998;123:127-30.

29. Papachristou DN, Fortner JG. Adenocarcinoma of the gastric cardia: the choice of gastrectomy. Ann Surg. 1980;192:58-64.

30. Moreaux J, Msika S. Carcinoma of the gastric cardia: surgical management and long-term survival. World J Surg. 1988;12:229-35.

31. Graham D, Zucker E, Ishmil N, Coit D, Brennan M. Prospective assessment of short-term quality of life after total, distal or proximal gastrectomy for gastric cancer. J Clin Oncol. 2007; 25(18S):abstr 15020. 